\title{
A forecast model for a road network's section traffic capacity assessment on a territory of the cryolithozone in conditions of the climate change
}

\author{
A.N. Yakubovich ${ }^{1}$, Yu.V. Trofimenko ${ }^{2}$, I.A. Yakubovich ${ }^{1}$, E.V. Shashina ${ }^{2}$ \\ ${ }^{1}$ Operation and Servicing of Motor Vehicles Chair, Moscow Automobile and Road Construction State Technical University (MADI) \\ Leningradsky avenue, 64, Moscow, Russia, 125319 \\ ${ }^{2}$ Technosphere Safety Chair, Moscow Automobile and Road Construction State Technical University (MADI) \\ Leningradsky avenue, 64, Moscow, Russia, 125319
}

Article Info

Received Dec 23, 2018

\section{Keyword:}

Traffic capacity

Road network section

Permafrost zone

Climate change

Modelling

\begin{abstract}
A model is proposed in which the capacity of the road network section depends on the technical and operational condition of the road surface - the presence of sinkholes, potholes, ruts, as well as their predictive depth. Appearing of these defects on the road surface is associated with excessive thawing and permafrost soil settlement in the formation occurring under the influence of the climate change. The soil thawing depth is modelled on the basis of predictive climatic parameters during the full average year, and then the maximum thawing depth and the corresponding soil settlement is determined. Three main scenarios of the climate change are considered: temperature contrast increasing, uniform warming and their combination. The assumed value of warming or temperature contrast increasing is considered to be a random value distributed according to the normal law; the predicted decrease in the road section capacity is defined as a weighted average over the entire range of possible climate changes. According to the results of the numerical implementation of the model on the road network sections for natural and climatic conditions of Yakutia, it is shown that in the third scenario of the climate change the road network section capacity is predicted to decrease from $17 \%$ (the formation is dry sandy permafrost soil) to 50\% (the formation is clay soil of high humidity). The impact of natural and climatic features of the territory is predicted to be at a level up to $10 \%$ of the total reduction in the capacity of road network sections.
\end{abstract}

\section{Corresponding Author:}

Yu.V. Trofimenko,

Technosphere Safety Chair,

Moscow Automobile and Road Construction State Technical University (MADI),

Leningradsky avenue, 64, Moscow, Russia, 125319.

Email: ywtrofimenko@mail.ru

\section{Introduction}

Modelling of traffic flows carried out both for a separate section of the road network and within the boundaries of connected sections of the road network on a certain area of the territory involves taking into account a large number of random events and phenomena that directly affect the characteristics of traffic flows. This imposes certain restrictions on the modelling methods that allow obtaining correct results. One of the effective approaches is the use of fuzzy logic, which is shown, for example, in [1]. Another group of methods, which has become widespread recently, is based on the cellular automata theory [2], which allows to assess quantitative a wide range of the transport flow parameters. Modelling of the velocities and the 
coefficients of the interaction between different types of vehicles in the flow is presented in [3]; the estimation of different parameters of traffic flows on the linear sections and junctions of the road network is made in [4]. The state of the external (natural) environment (natural and climatic factors) also influences the characteristics of traffic flows and should be fully taken into account during their modelling. Adverse external conditions can have a negative impact on the average speed of traffic flows, the capacity of some sections of the road network. Studies carried out in [5] are aimed at establishing quantitative relationships between climatic factors and the parameters of traffic flows. It is shown that during high-intensity rainfall, the average journey delay can be up to 35 minutes in a section less than $2 \mathrm{~km}$ long. Simultaneously with the deterioration of such indicators as the flow density, its speed and delay, the safety coefficient of the corresponding road network section decreases [6]. Meanwhile, regardless of the adverse weather effects intensity, there are no changes in the parameters of the cargo traffic flow. As shown in [7], for freight vehicles, flow parameters are stable regardless of the severity of winter weather conditions, such as snowfall and temperature (microscopic factors), or changes in months and seasons of the year (macroscopic factors). Accordingly, the negative impact of external conditions, even quite short-term, are on full display in relation to the entire traffic flow which is steadily formed in the corresponding road network section.

In cases where the external conditions initiate the road surface defects appearing, the adverse effects are significantly increasing, and the reduction in the road network section capacity becomes long-term. Studies [8] found that the formation of water and sand flows on the slopes is possible at a rainfall intensity starting from $4.14 \mathrm{~mm} / \mathrm{h}$, after which the slope erosion increases; the road profiles on sandy soils are especially vulnerable.

Frequency increase of adverse external influences, primarily due to the climate change, is the most dangerous for the road network functioning [9]. As shown in [10], the global climate change, although of a probabilistic nature, leaves no doubt about the progressive increase of the average annual air temperature on the planet. The magnitude of warming expected before 2050 is estimated to be between $1 \ldots 2$ and 6 ...8 Celsius degrees. A natural consequence of this process, as shown in [11], is the degradation of permafrost and cryolitic soils, which cover 2/3 of the territory of the Russian Federation. Reduction of bearing capability and increase of deformation of thawing permafrost soils creates a real threat to the transport infrastructure located on them. The analysis of climatic risks, carried out in [12], shows that the excess thawing of formation soil is predicted with a high degree of probability in the coming years for the exploited cryolithozone road network sections, the design of which took into account outdated data on climatic parameters. As a result, subsidence and sinkholes of the road surface will become widespread, causing a decrease in average speeds of traffic flows and a corresponding decrease in the capacity of certain sections and the road network as a whole located in the cryolithozone. The methodology of numerical simulation of the depth of the excess thawing of permafrost soil determined for different scenarios of expected climate change is shown in [13]. In this article, on the basis of the above-mentioned methodology, a quantitative assessment of the predicted decrease in the capacity of certain sections and the network of the cryolithozone roads is made.

\section{Prediction technique of the road network section condition}

The main indicator of the cryolithozone road network section condition is its temperature regime. In the simulation, a road section in the embankment is considered, which is divided into three zones (Fig. 1):

- road surface, the thickness of which, as well as the type of material used, affects the heat exchange processes with the underlying layers of the road structure;

- thawing zone with a lower boundary at a depth $H$, corresponding to the climatic conditions accepted during the design and construction of the road section (the base climate);

- additional thawing zone with depth $\Delta H$ resulting from warming (corresponding to the changed climate). Within the limits of normative thawing depth $H$ soil settlement in the formation is considered absent $(h=0)$ as this soil was placed as a part of the formation in the thawed state. Additional settlement of thawed soil, which was initially in the frozen state, occurs when it thaws in zone $c$ (Fig. 1), and leads to uneven subsidence of the overlying layers of soil in the formation and the capping layers of the road surface. As a result, numerous chaotically located sinkholes are formed on the road surface, causing the road section capacity decrease. In the simulation of heat transfer the road body is divided into separate design elements (types) (Fig. 1):

- type 1: main soil in the formation for which heat exchange is possible (heat input and release);

- type 2: soil on the vertical boundary of the simulated mass; the presence of elements of this type eliminates the "thermos effect" (heat accumulation) during the simulation; 
- type 3: air which is in contact with the upper boundary of the soil mass; the temperature change of these design elements is taken into account in accordance with the daily and annual changes in air temperature in the area under consideration;

- type 4: non-designed elements (air which is not in contact with soil); the presence of elements of this type derived from the rectangular shape of the modelling area.
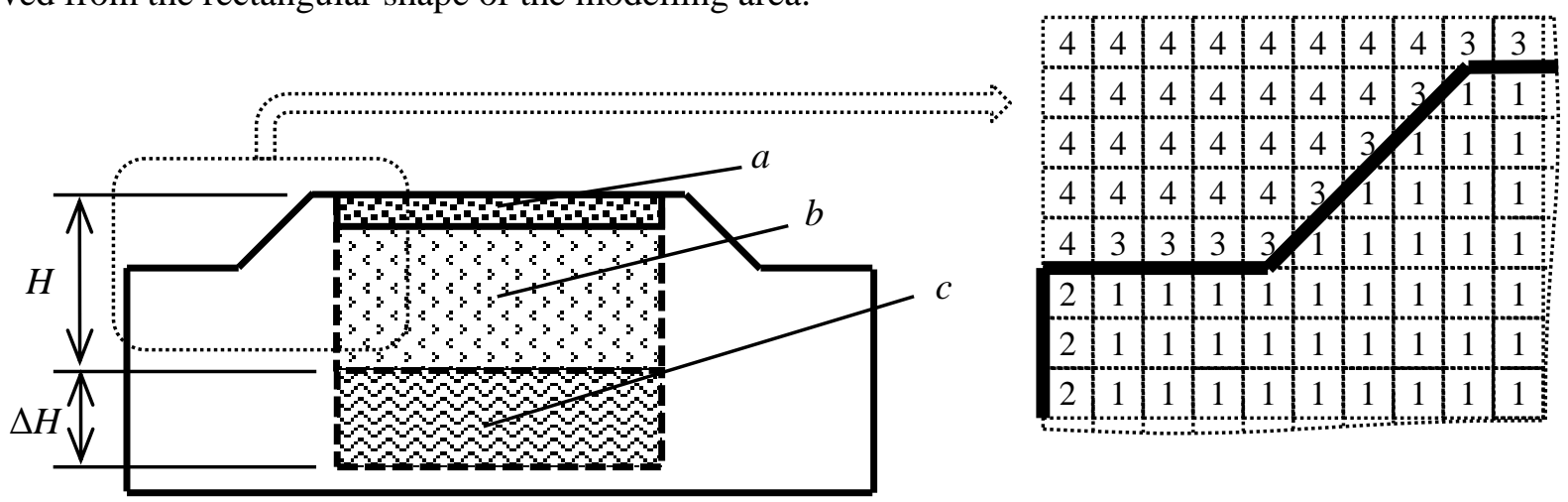

Figure 1. The scheme of the model for calculating the depth of soil thawing in the formation (a-the road surface, $\mathrm{b}$ - thawing zone for the base climate, $\mathrm{c}$ - zone of additional thawing with climate warming, 1-4 - types of design elements in the simulation of heat transfer).

The amount of heat $Q_{i-j}$, obtained or given by the designed element of $i$-th type contacting the element of $j$-th type during time $\Delta \tau$, during which the temperature of these elements is considered unchanged, is calculated by the formulas:

$$
\left.\begin{array}{c}
Q_{1-1}=\frac{0.5\left(\lambda_{A}+\lambda_{B}\right)}{\delta_{x / y}}\left(t_{A}-t_{B}\right) \delta_{y / x} \delta_{z} \Delta \tau, \\
Q_{2-1}=Q_{1-1}, \\
Q_{1-2}=0, \\
Q_{1-3}=18 v^{0.578}\left(t_{A}-t_{B}\right) \delta_{x} \delta_{z} \Delta \tau, \\
Q_{3-1}=0,
\end{array}\right\}
$$

where $\lambda_{A}$ and $t_{A}$ - the temperature-dependent thermal conductivity of soil and the temperature for element $A$; $\lambda_{B}$ and $t_{B}$ - the same for element $B ; \delta_{\mathrm{x}}, \delta_{\mathrm{y}}, \delta_{\mathrm{z}}$ - the spatial resolution of the model in the direction of the corresponding axis; $\Delta \tau$ - the quantum of simulation time; $v$ - the average wind speed during the period $\Delta \tau$.

Modelling of the temperature regime of soil in the formation is carried out during the full year, which subsequently allows to identify the greatest depth of thawing in a year $(H+\Delta H)$ and to determine the maximum settlement of thawed soil in zone $c$.

\section{The climate change scenarios}

The climatic parameters that determine the temperature regime of soil in the formation, according to (1), are air temperature and wind speed. When modelling the base climate, these parameters are taken from the results of long-term instrumental observations displayed in the territorial climate reference-books. Since the statistical data on temperature and wind speed are averaged over the individual months of the year, the procedure is performed to determine the values of these parameters for all the quantum of the simulation time:

- maximum, minimum, and average daily air temperature values are approximated with cubic splines, with each average monthly value referring exactly to the middle of the corresponding month;

- cubic splines are used to determine the air temperature values (maximum $t_{\max }$, minimum $t_{\min }$ and average $t_{\text {mid }}$ ) for each day of the average year;

- for each day, a graph of the daily course of the air temperature corresponding to a certain combination of $t_{\max }, t_{\min }$ and $t_{\text {mid }}$ is constructed, using this graph the air temperature for each quantum of the simulation time $\Delta \tau$ is determined.

The aim of the climate change modelling is increasing the air temperature values corresponding to the base climate. The predicted warming intensity is determined by a priori assigned parameter $\Delta t$. Three scenarios of the climate change were considered: 
- scenario 1: the climate temperature contrast increasing. In this scenario, all average monthly positive temperatures increase by $\Delta t$ and all negative temperatures decrease by $\Delta t_{l}$. The value of $\Delta t_{l}$ is determined from the condition of maintaining the average annual temperature at the level corresponding to the base climate;

- scenario 2: uniform warming. All average monthly temperatures increase by $\Delta t$;

- scenario 3: combination of warming and temperature contrast increasing. All positive average monthly temperatures increase by $2 \Delta t$, and the change in negative temperatures is so that the average annual temperature increases by $\Delta t$.

The lack of accurate quantitative forecasts of the expected intensity of the climate change $\Delta t$ leads to the need for a probabilistic approach. The parameter $\Delta t$ is considered to be a random variable distributed according to the normal law, and its a priori set value is interpreted as the average value of this distribution. Possible deviations of $\Delta t$ from its mean value exceeding $2^{\circ} \mathrm{C}$ are considered to be possible no more than once every 50 years; this condition determines the variability of the normal distribution with an average value of $\Delta t$ (Fig. 2).

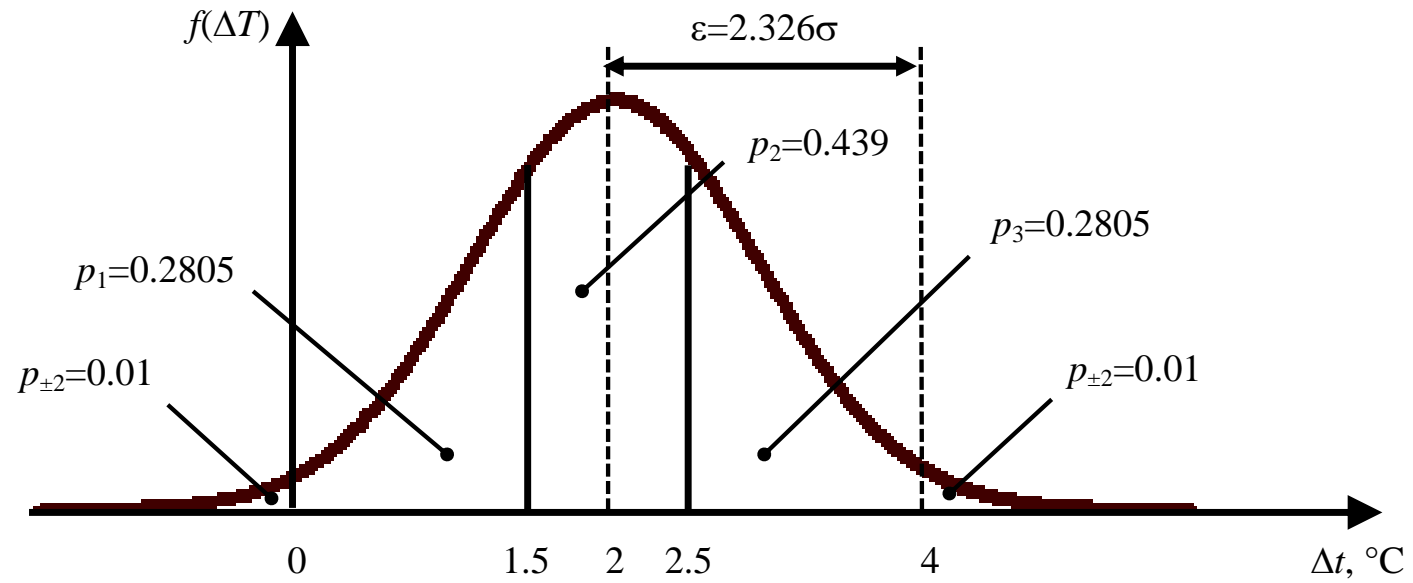

Figure 2. Simulation of a probabilistic nature for the climate change intensity attribute $\Delta \mathrm{t}$.

\section{The road section capacity assessment}

The total settlement of thawing permafrost soil occurring under the influence of the climate change in the zone $c$ (Fig. 1) is determined by the formula:

$$
\Delta h=\delta_{x} \sum_{t_{i}>t_{b f}} e_{i}
$$

where $\delta_{x}$ - the spatial resolution of the model in the vertical direction; $t_{i}$ and $e_{i}$ - the temperature and relative settlement during thawing for the $i$-th vertical layer of soil in the zone $c ; t_{b f}$ - the freezing temperature of soil. The maximum possible capacity of the road section $U$ corresponding to the condition of the road surface within the conditions of the base climate (when $\Delta h=0$ ) is taken as 1 (corresponds to the normative technical condition). The value of mass appearing subsidence in the formation (depth of potholes on the road surface), when the operation of the road is impossible $(U=0)$, is set to $10 \mathrm{~cm}$. Dependence of the capacity $U$ (in relative units) on the excess subsidence $\Delta h$ is shown in Fig. 3.

When predicting the value of the capacity of the road section that is subject to the climate change, it is necessary to consider several possible implementations of the random variable $\Delta t$, for each of which the excess thawing of soil $\Delta h$ and the capacity $U$ are modelled. Determination of the weighted average value of the capacity for three implementations of $\Delta t$ is made by the formula:

$$
U=\sum_{j=1}^{3} u\left(\Delta t_{j}\right) p_{j}
$$

where $\Delta t_{j}-j$-th simulated value for the attribute of intensity of the climate change; $p_{j}-$ probability $\Delta t_{j}$ (Fig. 2). 


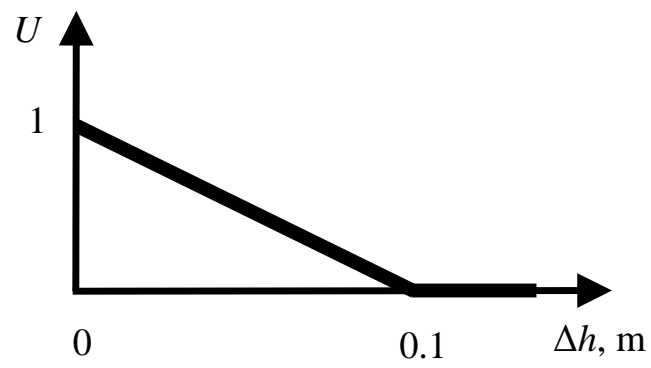

Figure 3. Dependence of the relative value of the road section capacity $U$ on the soil subsidence in the formation at its excess thawing $\Delta h$.

\section{Numerical implementation of the model for natural and climatic conditions of Yakutia}

The forecast model was tested for different climatic conditions and soil types on the territory of Yakutia (Table 1).

Table 1. Predictive decrease in the cryolithozone road sections capacity due to possible road surface destruction as a result of the climate change.

\begin{tabular}{lcccccc}
\hline \multirow{2}{*}{ Locality } & \multirow{2}{*}{ Coordinates $(B ; L)$} & \multirow{2}{*}{ Scenario } & \multicolumn{5}{c}{ Soil type } \\
\cline { 4 - 7 } & & & Dry sand & Damp sand & Dry clay & Damp clay \\
\hline Sahandzha & $(69.71 ; 128.19)$ & 1 & 0.90 & 0.86 & 0.86 & 0.84 \\
& & 2 & 0.88 & 0.85 & 0.83 & 0.78 \\
\multirow{3}{*}{ Darpir } & 3 & 0.78 & 0.72 & 0.67 & 0.60 \\
& & 1 & 0.89 & 0.90 & 0.85 & 0.76 \\
& & 2 & 0.86 & 0.85 & 0.82 & 0.73 \\
Yakutsk & $(62.02 ; 147.72)$ & & 0.77 & 0.75 & 0.66 & 0.50 \\
& & 1 & 0.93 & 0.88 & 0.86 & 0.79 \\
& & 2 & 0.90 & 0.87 & 0.80 & 0.74 \\
Tommot & $(58.96 ; 129.29)$ & 1 & 0.83 & 0.76 & 0.68 & 0.57 \\
& & 2 & 0.90 & 0.87 & 0.86 & 0.76 \\
& & 3 & 0.83 & 0.75 & 0.79 & 0.74 \\
\hline
\end{tabular}

In all cases, the mean intensity of the climate change was set to $\Delta t=2^{\circ} \mathrm{C} .3$ implementations of $\Delta t:+{ }^{\circ} \mathrm{C}$, $+2{ }^{\circ} \mathrm{C}$, and $+3{ }^{\circ} \mathrm{C}$ were considered while determining the weighted average value of $U$; the probabilities of each implementation occurrence are shown in Figure 2. It was found that the greatest reduction in the cryolithozone road network sections capacity due to the increased probability of destruction of the road surface as a result of possible climatic changes on damp clay soils can be $40 \ldots 50 \%$ as compared to the baseline scenario (in the absence of the climate change). On sandy soils, under these conditions, the roads capacity reduction can be about $17 . .23 \%$.

\section{Conclusion}

The proposed model provides a predictive quantitative assessment for the cryolithozone roads capacity in a wide range of possible climate changes. As a result, timely planning of engineering and technical measures aimed at ensuring the required technical and operational indicators of the road network in the conditions of the climate change becomes possible.

According to the results of the numerical implementation of the model, it can be seen that the scenario of the climate change, involving a combination of warming and simultaneous increasing in temperature contrast, is the most dangerous. The expected reduction in the Yakutia road sections capacity can reach 50\%, while the most unfavourable are clay permafrost soils at the formation, especially at their high humidity. Natural and 
climatic features of the territory have a significant impact on the cryolithozone roads capacity reduction, which, in the case of the Yakut region, is $10 \%$ or more to the projected value of $U$.

\section{References}

[1] Nikolaev A.B., et al. "Fuzzy Algorithm for the Detection of Incidents in the Transport System," Int. J. Environmental and Science Education, vol. 11(16), pp. 9039-9059, 2016.

[2] Buslaev A.P., Tatashev A.G. and Yashina M.V. "On cellular automata, traffic and dynamical systems in graphs," Int. J. Engineering and Technology, vol. 7 (2.28), pp. 351-356, 2018.

[3] Pandey G., Rao K.R. and Mohan D. "Modeling vehicular interactions for heterogeneous traffic flow using cellular automata with position preference," J. Mod. Transport, vol. 25(3), pp. 163-177, 2017.

[4] Chechina A., et al. "Traffic Flow Modeling on Road Networks Using Cellular Automata Theory," Int. J. Engineering and Technology, vol. 7 (2.28), pp. 225-227, 2018.

[5] Etikaf H., Syed I.A. and Mir S.A. "Modeling the effects of rainfall on vehicular traffic," J. Mod. Transport, vol. 26(2), pp. 133-146, 2018.

[6] Yue Y, Luo S. and Luo T. "Micro-simulation model of two-lane freeway vehicles for obtaining traffic flow characteristics including safety condition," J. Mod. Transport, vol. 24(3), pp. 187-195, 2016.

[7] Roh H.J. and Sharma S. "Microscopic and macroscopic diagnosis of the effect of winter weather conditions on distribution pattern of truck types in regional commuter road," J. Mod. Transport, vol. 26(1), pp. 57-71, 2018.

[8] Tangjin Ye, et al. "Analog modeling of sand slope stability with different precipitation conditions," $J$. Mod. Transport, vol. 26(3), pp. 200-208, 2018.

[9] Yakubovich A.N. and Trofimenko Yu.V. "Methology of forecasting natural emergencies risks in road network," Safety in Technosphere, vol. 2, pp. 73-82, 2015. (in Russian)

[10] Gruza G.V. and Rankova Eh.Ya. "Probabilistic assessment of observed and expected climate changes in the Russian Federation: air temperature," Problems of ecological monitoring and modeling of ecosystems, vol. 24, pp. 43-70, 2011. (in Russian).

[11] Anisimov O.A. "Probabilistic and statistical modeling of the seasonal layer power in the conditions of modern and future climate," Cryosphere Of The Earth, vol. XIII (3), pp. 36-44, 2009. (in Russian).

[12] Yakubovich A.N., Trofimenko Yu.V. and Yakubovich I.A. "Modeling and assessment of natural and man-made risks in the road transport complex", MADI Publishers, Moscow, 232 p., 2018. (in Russian).

[13] Yakubovich A.N., Trofimenko Yu.V. and Pospelov P.I. "Principles of developing a procedure to assess consequences of natural and climatic changes for transport infrastructure facilities in permafrost regions," Transportation Research Procedia, vol. 36, pp. 810-816, 2019. 